\title{
Image-guided stereotactic radiosurgery for treatment of spinal hemangioblastoma
}

\author{
*James Pan, BS, ${ }^{1}$ Allen L. Ho, MD,1 Myreille D’Astous, MD, PhD, ${ }^{1}$ Eric S. Sussman, MD, ${ }^{1}$ \\ Patricia A. Thompson, MSN, ${ }^{1}$ Armine T. Tayag, MSN, ${ }^{1}$ Louisa Pangilinan, BSN, ${ }^{1}$ \\ Scott G. Soltys, MD, ${ }^{2}$ Iris C. Gibbs, MD, ${ }^{2}$ and Steven D. Chang, MD ${ }^{1}$ \\ Departments of ${ }^{1}$ Neurosurgery and ${ }^{2}$ Radiation Oncology, Stanford University School of Medicine, Stanford, California
}

\begin{abstract}
OBJECTIVE Stereotactic radiosurgery (SRS) has been an attractive treatment option for hemangioblastomas, especially for lesions that are surgically inaccessible and in patients with von Hippel-Lindau (VHL) disease and multiple lesions. Although there has been a multitude of studies examining the utility of SRS in intracranial hemangioblastomas, SRS has only recently been used for spinal hemangioblastomas due to technical limitations. The purpose of this study is to provide a long-term evaluation of the effectiveness of image-guided radiosurgery in halting tumor progression and providing symptomatic relief for spinal hemangioblastomas.
\end{abstract}

METHODS Between 2001 and 2011, 46 spinal hemangioblastomas in 28 patients were treated using the CyberKnife image-guided radiosurgery system at the authors' institution. Fourteen of these patients also had VHL disease. The median age at treatment was 43.5 years (range 19-85 years). The mean prescription radiation dose to the tumor periphery was $21.6 \mathrm{~Gy}$ (range $15-35 \mathrm{~Gy}$ ). The median tumor volume was $0.264 \mathrm{~cm}^{3}$ (range $0.025-70.9 \mathrm{~cm}^{3}$ ). Tumor response was evaluated on serial, contrast-enhanced CT and MR images. Clinical response was evaluated by clinical and imaging evaluation.

RESULTS The mean follow-up for the cohort was 54.3 months. Radiographic follow-up was available for 19 patients with 34 tumors; $32(94.1 \%)$ tumors were radiographically stable or displayed signs of regression. Actuarial control rates at 1,3 , and 5 years were $96.1 \%, 92.3 \%$, and $92.3 \%$, respectively. Clinical evaluation on follow-up was available for 13 patients with 16 tumors; $13(81.2 \%)$ tumors in 10 patients had symptomatic improvement. No patient developed any complications related to radiosurgery.

CONCLUSIONS Image-guided SRS is safe and effective for the primary treatment of spinal hemangioblastomas and is an attractive alternative to resection, especially for those with VHL disease.

https://thejns.org/doi/abs/10.3171/2016.10.FOCUS16361

KEY WORDS hemangioblastoma; stereotactic radiosurgery; CyberKnife; von Hippel-Lindau

$\mathrm{H}$ EMANGIOBLASTOMAS are benign vascular neoplasms of the central nervous system and are classified as meningeal tumors of uncertain origin. ${ }^{4,19} \mathrm{He}$ mangioblastomas present either as sporadic lesions or in $20 \%-25 \%$ as manifestations of von Hippel-Lindau disease (VHL) due to a loss of function mutation in the VHL tumor suppressor gene. ${ }^{15,25}$ Sporadic lesions are almost always associated with the cerebellum, whereas VHL lesions can occur anywhere along the cerebellum, brainstem, and spinal cord. ${ }^{12}$ Symptoms of hemangioblastomas usually manifest as consequences of mass effect compression of local structures. ${ }^{2}$ Spinal cord lesions are most often associated with pain, which also may be followed by sensory loss, and less commonly motor symptoms. ${ }^{18}$

Historically, fractionated radiation therapy was indicated for inoperable, residual, or recurrent tumors. ${ }^{23,24}$ More recently, stereotactic radiosurgery (SRS) has been used as a minimally invasive primary, adjuvant, or salvage treatment for hemangioblastoma. ${ }^{16} \mathrm{SRS}$ is advantageous in that it is relatively noninvasive, has the ability to target very small tumors, and has lower morbidity than resection. The use of image-guided radiosurgery systems is becoming

ABBREVIATIONS ARE = adverse radiation event; Dmax = maximum point dose; LINAC = linear accelerator; SRS = stereotactic radiosurgery; VHL = von Hippel-Lindau. SUBMITTED August 31, 2016. ACCEPTED October 14, 2016.

* Mr. Pan and Dr. Ho contributed equally to this work. 
increasingly popular for the treatment of spinal hemangioblastomas and intramedullary spinal tumors alike. The utility of radiosurgery and image-guided systems has been further supported by case series, which continue to show favorable outcomes. ${ }^{1,5,7,9,10,17,20-22}$ Furthermore, a recent systematic review surveying 10 papers that discussed radiosurgical treatment for intramedullary spinal tumors revealed that the CyberKnife (Accuray) was used in 87\% of cases and afforded favorable clinical and radiological outcomes. ${ }^{8}$ We present a large prospective cohort of spinal hemangioblastomas treated with radiosurgery.

\section{Methods \\ Patients}

Between 2000 and 2011, 46 spinal hemangioblastomas in 28 patients were treated with SRS at Stanford Health Care. The clinical information was maintained in an institutional review board-approved prospective database and was retrospectively reviewed. Clinical data collected included patient demographics, date of hemangioblastoma diagnosis and its location, previous treatments (e.g., neurosurgical procedures and radiotherapy), presenting symptoms, time to last follow-up, symptoms at follow-up, and radiographic evaluation at follow-up. Radiosurgery-related data included total SRS prescription dose, maximum point dose (Dmax), isodose line, fractions administered to the tumor, tumor volume, and treated volume.

\section{Stereotactic Radiosurgery}

All treatments were carried out using the CyberKnife image-guided robotic radiosurgery system. Patient immobilization was achieved using an Aquaplast face mask (WFR/Aquaplast) for cervical spine lesions or a vacuumset moldable Styrofoam immobilization cushion (Vac $\mathrm{Bag}, \mathrm{MedTech}$ ) for lesions of the thoracic or lumbar spine. Supine contrast-enhanced 1.25-mm-thick CT scans were obtained through the spinal region of interest. Contiguous axial 2.0-mm-thick stereotactic MR images were acquired with the patient in the supine position. Both CT and MR image sets were integrated into the treatment-planning workstation to delineate the tumor. The target volume and other critical structures were contoured slice by slice on the treatment-planning CT. The spinal cord was contoured at least 1 vertebral level above and below each target lesion. Treatment plans were generated with iterative inverse treatment-planning software.

Prior to radiosurgical imaging, patients with tumors caudal to C-2 and who were treated before September 2004 underwent minimally invasive surgical placement of 3-5 small stainless steel fiducial markers into the posterior elements of adjacent vertebral bodies. After September 2004, bony anatomy alone was used for target localization with the Xsight skeletal structure tracking system (Accuray). The process of real-time imaging acquisition and dynamic targeting has been described previously. ${ }^{6}$

\section{Follow-Up Monitoring}

Patients underwent follow-up with clinical examinations at around 3 and 6 months after treatment. Patients living outside the immediate area were followed remotely
TABLE 1. Summary of cohort, treatment, and follow-up characteristics

\begin{tabular}{lc}
\hline \multicolumn{1}{c}{ Variable } & Value \\
\hline Clinical characteristics & 28 \\
\hline No. of patients & 46 \\
\hline No. of tumors & $14(50 \%)$ \\
\hline No. of patients w/ VHL disease & $14(50 \%)$ \\
\hline Male sex & \\
\hline Presenting symptoms, no. & 4 \\
\hline Motor & 19 \\
\hline Sensory & 5 \\
\hline Mixed & 1 \\
\hline Asymptomatic & 17 \\
\hline Tumor location, no. & 24 \\
\hline Cervical & 5 \\
\hline Thoracic & \\
\hline Lumbar & $43.5(19-85)$ \\
\hline Radiosurgical characteristics & $21.6(15-35)$ \\
\hline Median age at treatment (range), yrs & $28.1(18.1-42.7)$ \\
\hline Mean prescription dose (range), Gy & $77.6(68-100)$ \\
\hline Mean Dmax (range), Gy & $0.264(0.025-70.9)$ \\
\hline Mean isodose line (range), \% & $54.3(3-157)$ \\
\hline Median tumor vol (range), cm ${ }^{3}$ & $96.1,92.3, \& 92.3$ \\
\hline Follow-up characteristics & \\
\hline Mean follow-up (range), mos & \\
\hline Local control rates (at 1, 3, \& 5 yrs), \% & \\
\hline
\end{tabular}

by their referring physician, and progress reports as well as follow-up imaging studies were forwarded to Stanford for evaluation. Follow-up imaging studies were obtained every 3-6 months. Radiographic evaluation and clinical judgment of tumor stability, progression, regression, or radiation necrosis were made by treating clinician (radiation oncologist and/or neurosurgeon). This categorization of treatment outcomes based on radiographical and clinical evidence reflects what was ultimately put into practice and what will be most generalizable to other clinicians in a practice scenario. The actuarial local control rates were calculated using the Kaplan-Meier method. Statistical analysis was performed using the Python SciPy and lifelines packages.

\section{Results \\ Cohort Characteristics}

The cohort of patients consisted of 14 men and 14 women, with a median age of 43.5 years (range 19-85 years) at the time of radiosurgery (Table 1). Fourteen (50\%) of these patients also had VHL disease. The mean number of tumors per patient was 1.64. Twenty patients had undergone previous neurosurgical operations related to hemangioblastoma resection, and 12 patients had previously received radiotherapy (Table 2). Presenting symptoms were classified as pure motor, pure sensory, mixed, or asymptomatic (4 motor, 19 sensory, 5 mixed, and 1 asymptomatic). 
TABLE 2. Individual patient clinical characteristics

\begin{tabular}{|c|c|c|c|c|c|c|c|c|}
\hline $\begin{array}{l}\mathrm{Pt} \\
\text { No. }\end{array}$ & $\begin{array}{l}\text { Case } \\
\text { No. }\end{array}$ & Sex & VHL & Site & $\begin{array}{c}\text { Age at } \\
\text { SRS (yrs) }\end{array}$ & Presenting Symptoms & $\begin{array}{c}\text { Previous } \\
\text { Neurosurgery }\end{array}$ & $\begin{array}{c}\text { Previous } \\
\text { Radiotherapy }\end{array}$ \\
\hline 1 & 1 & M & No & L2-3 & 60 & Chronic low-back pain, lack of bladder control & Yes & No \\
\hline 2 & 2 & $\mathrm{~F}$ & No & $\mathrm{T}-9$ & 30 & Midthoracic pain & No & No \\
\hline 3 & 3 & M & No & T-6 & 64 & Lower-extremity weakness \& numbness, midthoracic pain & Yes & Yes \\
\hline \multirow[t]{6}{*}{4} & $4-1$ & $\mathrm{~F}$ & No & $\mathrm{C} 1-2$ & 57 & Weakness \& fine motor dysfunction & Yes & Yes \\
\hline & $4-2$ & $\mathrm{~F}$ & No & C3-4 & 59 & & & \\
\hline & $4-3$ & $\mathrm{~F}$ & No & C-4 & 59 & & & \\
\hline & $4-4$ & $\mathrm{~F}$ & No & $\mathrm{T}-1$ & 59 & & & \\
\hline & $4-5$ & $\mathrm{~F}$ & No & T-6 & 59 & & & \\
\hline & $4-6$ & $\mathrm{~F}$ & No & $\mathrm{T}-11$ & 59 & & & \\
\hline 5 & 5 & M & No & $\mathrm{T} 1-2$ & 77 & Weakness in the hand & Yes & No \\
\hline 6 & 6 & $\mathrm{~F}$ & No & C4-5 & 59 & Neck pain, numbness & No & No \\
\hline 7 & 7 & M & No & $\mathrm{T}-2$ & 39 & Dizziness, nausea, numbness, lack of bladder control & Yes & No \\
\hline \multirow[t]{3}{*}{8} & $8-1$ & $\mathrm{~F}$ & No & $\mathrm{L}-2$ & 46 & Lower-back pain & Yes & No \\
\hline & $8-2$ & $\mathrm{~F}$ & No & $\mathrm{T}-5$ & 46 & & & \\
\hline & $8-3$ & $\mathrm{~F}$ & No & T-9 & 46 & & & \\
\hline \multirow[t]{4}{*}{9} & $9-1$ & M & No & L3-S2 & 43 & Numbness in foot \& buttocks & Yes & No \\
\hline & $9-2$ & M & No & C-5 & 43 & & & \\
\hline & $9-3$ & M & No & $\mathrm{T}-2$ & 43 & & & \\
\hline & $9-4$ & M & No & $\mathrm{L}-2$ & 43 & & & \\
\hline 10 & 10 & $\mathrm{~F}$ & No & $\mathrm{T}-11$ & 51 & Weakness in lower extremity & Yes & No \\
\hline 11 & 11 & M & No & $\mathrm{T}-7$ & 37 & Pain from umbilicus to the rt back & Yes & No \\
\hline 12 & 12 & $\mathrm{~F}$ & No & $\mathrm{C} 7-\mathrm{T} 1$ & 60 & Neck pain, radiculopathy in It hand & Yes & No \\
\hline 13 & 13 & M & No & $\mathrm{T}-7$ & 50 & Midthoracic pain & No & Yes \\
\hline 14 & 14 & $\mathrm{~F}$ & No & $\mathrm{C} 6-\mathrm{T} 1$ & 85 & Numbness, balance problems & Yes & \\
\hline 15 & 15 & M & Yes & C-2 & 43 & Tingling \& itching in extremities, hearing loss, tinnitus & Yes & Yes \\
\hline 16 & 16 & $\mathrm{~F}$ & Yes & C-5 & 19 & Headaches & No & Yes \\
\hline 17 & 17 & $\mathrm{~F}$ & Yes & $\mathrm{T} 7-8$ & 48 & $\begin{array}{l}\text { Tinnitus, headaches, dizziness, neck \& shoulder pain, } \\
\text { speech problems, balance problems }\end{array}$ & Yes & Yes \\
\hline \multirow[t]{2}{*}{18} & $18-1$ & M & Yes & $\mathrm{T}-2$ & 30 & Pain, numbness & No & No \\
\hline & $18-2$ & M & Yes & $\mathrm{T}-10$ & 33 & Numbness & Yes & Yes \\
\hline 19 & 19 & M & Yes & $\mathrm{C}-2$ & 61 & Numbness & No & No \\
\hline \multirow[t]{4}{*}{20} & $20-1$ & $\mathrm{~F}$ & Yes & $\mathrm{C} 2-4$ & 25 & Dizziness, sensory abnormalities & No & No \\
\hline & $20-2$ & $\mathrm{~F}$ & Yes & C-5 & 26 & & & \\
\hline & $20-3$ & $\mathrm{~F}$ & Yes & T6-7 & 31 & & & \\
\hline & $20-4$ & $\mathrm{~F}$ & Yes & T6-7 & 31 & & & \\
\hline \multirow[t]{3}{*}{21} & $21-1$ & $\mathrm{~F}$ & Yes & C6-7 & 28 & Headaches, numbness, pain & Yes & Yes \\
\hline & $21-2$ & $\mathrm{~F}$ & Yes & $\mathrm{T}-7$ & 28 & & & \\
\hline & $21-3$ & $\mathrm{~F}$ & Yes & $\mathrm{T}-12$ & 30 & & & \\
\hline 22 & 22 & $\mathrm{~F}$ & Yes & T-9 & 25 & Tingling, pain & Yes & Yes \\
\hline 23 & 23 & M & Yes & $\mathrm{C}-2$ & 28 & Weakness & No & No \\
\hline 24 & 24 & M & Yes & C-3 & 38 & Pain, weakness & Yes & Yes \\
\hline \multirow[t]{2}{*}{25} & $25-1$ & M & Yes & $\mathrm{T}-1$ & 44 & Numbness & Yes & Yes \\
\hline & $25-2$ & M & Yes & T-12 & 44 & & & \\
\hline \multirow[t]{2}{*}{26} & $26-1$ & M & Yes & T-5 & 20 & Asymptomatic & No & No \\
\hline & $26-2$ & M & Yes & L-1 & 21 & & & \\
\hline 27 & 27 & $\mathrm{~F}$ & Yes & C-6 & 47 & Weakness, spasticity, balance problems & Yes & Yes \\
\hline 28 & 28 & $\mathrm{~F}$ & Yes & C6-7 & 44 & Numbness, ataxia, weakness, headaches & Yes & No \\
\hline
\end{tabular}

$\mathrm{Pt}=$ patient. 
The locations of the spinal lesions were distributed as follows: 17 cervical, 24 thoracic, and 5 lumbar.

\section{Radiosurgical Treatment}

A mean dose of 21.6 Gy (range 15.0-35.0 Gy) was prescribed to the mean $77.6 \%$ isodose line (range $68.0 \%-$ $100.0 \%$ ). The mean Dmax was 28.1 Gy (range 18.1-42.7 Gy). Treatment was delivered in 1-5 fractions (mean 1.8 fractions). The median tumor volume was $26.4 \mathrm{~mm}^{3}$ (range 2.6-7010 $\mathrm{mm}^{3}$ ) while the median treated volume was $25 \mathrm{~mm}^{3}$ (range $2.3-6344 \mathrm{~mm}^{3}$ ) (Table 1 and Supplemental Table 1).

\section{Radiographic Outcomes}

Nine patients with 12 tumors were lost to follow-up. One patient with 4 tumors (Patient 9) had successful follow-up for 1 tumor, but follow-up for the other 3 tumors was lost. Including the latter patient and the 1 tumor with follow-up (19 patients with 31) tumors, the mean followup was 54.3 months (range 3-157 months) (Supplemental Table 2). Actuarial local control rates at 1,3 , and 5 years were $96.1 \%, 92.3 \%$, and $92.3 \%$, respectively (Fig. 1).

If only patients with more than 2 years of follow-up were analyzed (11 patients with 23 lesions), actuarial local control rates at 36 and 60 months were both $100 \%$. Among the 7 spinal lesions with less than 2 years of follow-up imaging studies, 2 showed regression of tumor volume, 3 showed radiographic stability, and 2 showed radiographic progression. For the 23 spinal lesions with more than 2 years of follow-up, 3 lesions decreased in size, whereas 20 lesions remained unchanged in size.

\section{Effect of VHL Disease on Cohort Characteristics}

In our cohort, patients with VHL disease had a mean age of 38.8 years and non-VHL patients had a mean age of 53.1 years $(p=0.00001)$. VHL status did not seem to affect radiosurgery treatment parameters such as the prescription dose and isodose line. The mean tumor size of non-VHL tumors was $8.27 \mathrm{~cm}^{3}$, whereas for VHL tumors the mean tumor size was $0.53 \mathrm{~cm}^{3}(\mathrm{p}=0.04)($ Table 3$)$. This can be attributed to the fact that patients with VHL were monitored more closely, and thus lesions are detected earlier for intervention. This finding is consistent with data from other series. ${ }^{9}$

\section{Clinical Outcomes}

Clinical evaluation follow-up was available for 16 tumors in 13 patients. Thirteen $(81.2 \%)$ of these tumors in 10 patients had an associated improvement in symptoms, whereas 3 tumors in 3 patients showed no improvement or worsening of symptoms. However, 2 of the patients in whom symptoms did not improve had VHL disease and had additional tumor burden such as cerebellar and/or additional spinal cord lesions. No complications or adverse radiation events (AREs) related to SRS were observed after treatment or at subsequent follow-up intervals.

\section{Discussion}

This study details the prospective long-term outcomes

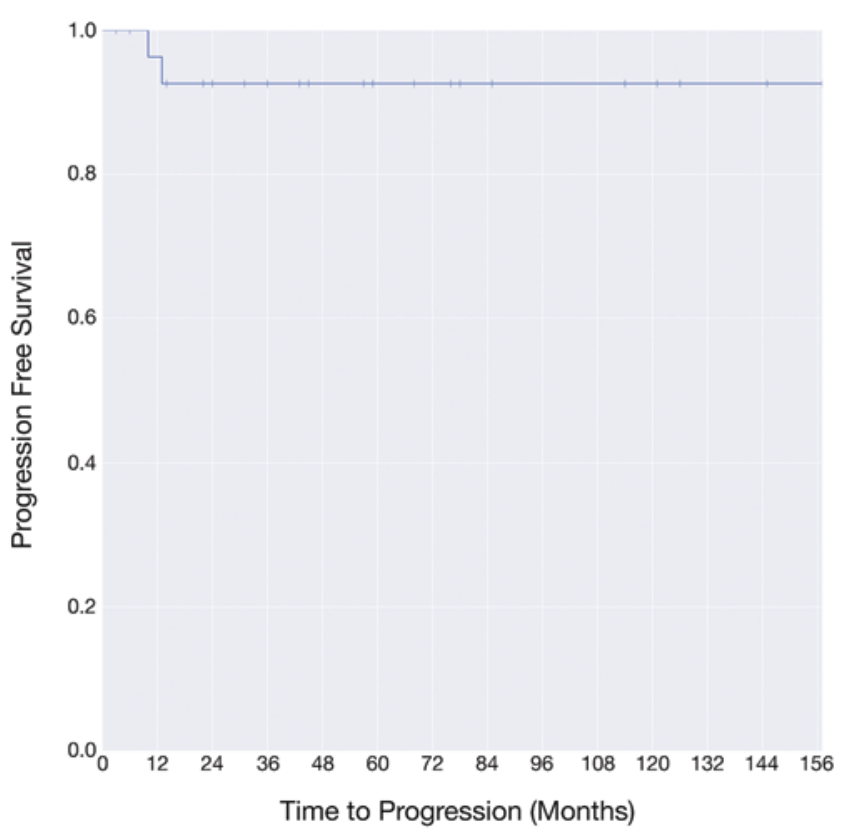

FIG. 1. Kaplan-Meier curve for radiographic progression.

of treatment of a large cohort of spinal hemangioblastomas treated via SRS at a single institution. In our treated cohort of 46 spinal hemangioblastomas in 28 patients, we report local control rates at 1,3 , and 5 years of $96.1 \%$, $92.3 \%$, and $92.3 \%$, respectively, with a mean follow-up of 54.3 months. Of treated tumors with clinical follow-up, 81.1\% demonstrated an improvement in symptoms, and there were no reported complications or AREs related to SRS. We have significantly improved control rates compared with our prior published intuitional experience of all hemagioblastomas (16 of which were spinal lesions) that had a median follow-up of 69 months and local control rates at 36 and 60 months of $85 \%$ and $82 \%$, respectively. ${ }^{14}$

Our results are comparable to or exceed those of similar recent studies of SRS treatment of spinal hemangioblastomas and also that of intracranial hemangioblastomas. A series of 9 patients with 20 spinal hemangioblastomas underwent image-guided linear accelerator (LINAC)-based SRS treatment and had favorable results. The estimated 4-year survival and solid local tumor control were $90 \%$ and $95 \%$, respectively. ${ }^{21}$ Another study examined CyberKnife treatment for a variety of benign spinal tumors including hemangioblastomas, neurogenic tumors, and meningiomas. In this series of 20 patients with 30 tumors, $57 \%$ of lesions regressed, while $33 \%$ of lesions were un-

TABLE 3. Effect on VHL status on cohort and treatment statistics

\begin{tabular}{lccl}
\hline \multicolumn{1}{c}{ Variable } & VHL Pts & Non-VHL Pts & p Value* \\
\hline Mean age at treatment, yrs & 38.8 & 53.1 & 0.00001 \\
\hline Mean prescription dose, Gy & 21.4 & 21.9 & 0.67 \\
\hline Mean Dmax, Gy & 27.9 & 28.2 & 0.83 \\
\hline Mean isodose line & $77.2 \%$ & $77.8 \%$ & 1 \\
\hline Mean tumor vol, $\mathrm{cm}^{3}$ & 0.53 & 8.27 & 0.04 \\
\hline
\end{tabular}

* Student t-test. 


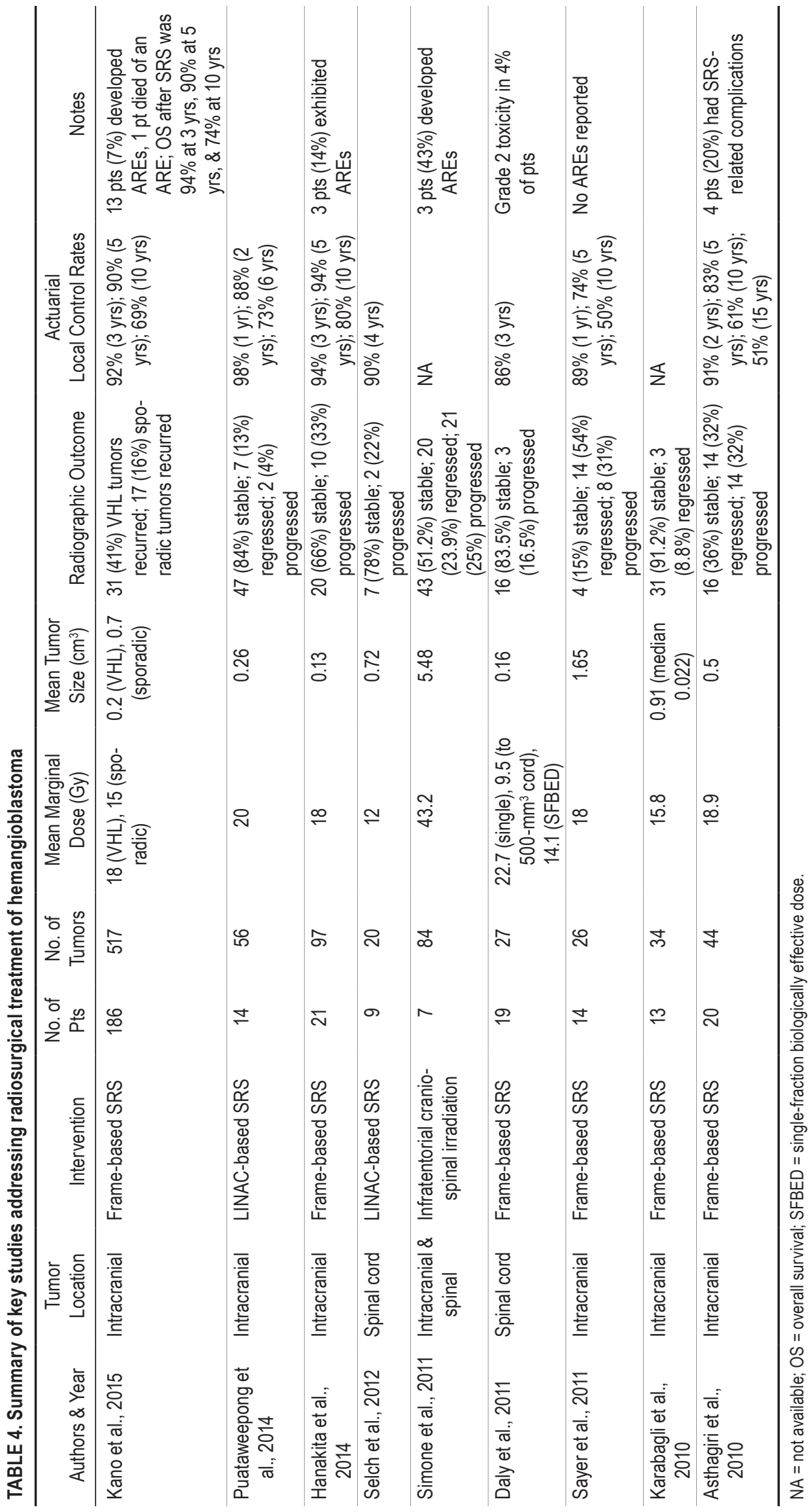


changed in size at a mean follow-up of 35.6 months. ${ }^{3}$ In a recent, large international, multicenter study addressing the treatment of intracranial hemangioblastomas, Kano et al. reported that at a mean of 9.5 years of follow-up, the overall survival after SRS treatment was $94 \%$ at 3 years, $90 \%$ at 5 years, and $74 \%$ at 10 years. ${ }^{9}$ Of the 335 hemangioblastomas treated that were associated with VHL disease, $134(40 \%)$ decreased in size and $79(43 \%)$ remained stable. Twenty-six (8\%) VHL-associated tumors and 31 $(16 \%)$ sporadic tumors progressed. Actuarial local control rates at 3,5 , and 10 years were $92 \%, 89 \%$, and $79 \%$ respectively. A summary of other key radiosurgical studies addressing exclusively hemangioblastomas is presented in Table 4.

\section{Complications}

Complications related to SRS treatment of spinal hemangioblastomas are rare, and worsening symptoms following treatment tend to be associated with additional intracranial or other spinal tumor burden seen most commonly in patients with VHL. No complications or adverse events were observed in our cohort and nearly $20 \%$ of patients with available clinical follow-up data in our cohort experienced worsening symptoms related to progression of disease or additional tumor burden. To minimize the risks of postoperative complications, an extensive preoperative workup is recommended. Diagnostic neuroimaging (e.g., MRI) of the brain and spinal cord is crucial, and laboratory studies are needed to determine a patient's VHL status. When adverse events related to treatment are observed, they are typically delayed and occur after treatment. The risk of AREs such as radiation necrosis is positively correlated to the dose and volume of the tumor treated. ${ }^{13} \mathrm{~Pa}-$ tients who present with preexisting edema around their tumor(s) may not be ideal candidates for radiosurgery, as treatment may worsen edema and exacerbate neurological symptoms. Overall, AREs are uncommon, manifesting in $0 \%-20 \%$ of patients treated with frame-based or LINACbased SRS (Table 4).

\section{Considerations for Patients With VHL Disease}

Previous studies have shown that VHL disease can be diagnosed in more than $30 \%$ of patients with newly discovered hemangioblastomas. ${ }^{11}$ Although VHL-associated lesions are detected earlier due to closer monitoring, Kano et al. recommends that small asymptomatic lesions be observed until radiographic progression or manifestation of clinical symptoms. ${ }^{9}$ However, there is considerable controversy regarding whether to treat asymptomatic lesions, as natural history studies have suggested that VHL-associated lesions have a quiescent phase and show a biphasic development pattern. Studies such as the one by Hanakita et al. advocate for the prompt treatment of newly discovered VHL-associated lesions as the benefits of treatment outweighs the risks of the lesion enlarging or causing neurological decline. ${ }^{7}$ Therefore, it is important to assess the indications and timing of treatment on a per-patient basis considering the patient's VHL status and the risk/benefit ratio of SRS. In our study, nearly all patients treated had symptomatic spinal lesions, including all patients with VHL, and $81 \%$ experienced an improvement in symptoms with no reported complications or adverse events. Thus, SRS treatment of symptomatic spinal hemangioblastomas in patients with VHL is a safe and effective option for tumor control and symptom management.

\section{Limitations of the Series}

Long-term follow-up is always essential to establish the efficacy and safety of SRS, especially for benign tumors where the reporting of short-term $(<5$ years) control rates does not necessarily translate to long-term remission. For example, in a series of 44 intracranial hemangioblastomas with a mean follow-up of 8.5 years, Asthagiri and colleagues reported local control rates of $91 \%$ and $51 \%$ at 2 and 10 years, respectively. The authors of that study cautioned that evidence of early radiographic regression and/ or stability may not reflect the final outcome. A large number of the patients in this series have also received prior radiotherapy; therefore, it is not possible to determine the overall radiation dose when treating in or near the prior radiation field. Furthermore, because half of the patients in this series have VHL disease, outcomes can be skewed by various comorbid tumors these patients may have such as renal cell carcinoma, pancreatic neuroendocrine tumors, and multiple hemangioblastomas in both the spinal cord and posterior fossa.

Due to the rareness of radiographic progression in our series, we were unable to calculate statistically significant factors associated with tumor progression. Other studies have reported that younger age, female sex, smaller lesions, and the absence of a cystic component of the tumor were factors that were associated with better tumor control. ${ }^{9}$

\section{Conclusions}

Stereotactic radiosurgery represents a safe, noninvasive treatment option, especially for VHL patients, in the armamentarium of multidisciplinary treatment of spinal hemangioblastomas. Our results demonstrate that SRS allows for excellent local control and symptomatic management of spinal hemangioblastomas in both VHL and sporadic lesions with an optimal safety profile. This study is consistent with and supplements prior reports of radiosurgical treatment for hemangioblastomas in that SRS is associated with an optimal local tumor control rate, low risk of adverse events and complications, and can be used to treat spinal cord lesions that pose high risk for resection.

\section{References}

1. Asthagiri AR, Mehta GU, Zach L, Li X, Butman JA, Camphausen KA, et al: Prospective evaluation of radiosurgery for hemangioblastomas in von Hippel-Lindau disease. Neuro Oncol 12:80-86, 2010

2. Bamps S, Calenbergh FV, Vleeschouwer SD, Loon JV, Sciot $\mathrm{R}$, Legius E, et al: What the neurosurgeon should know about hemangioblastoma, both sporadic and in Von Hippel-Lindau disease: a literature review. Surg Neurol Int 4:145, 2013

3. Chang UK, Rhee CH, Youn SM, Lee DH, Park SQ: Radiosurgery using the Cyberknife for benign spinal tumors: Korea Cancer Center Hospital experience. J Neurooncol 101:9199, 2011

4. Cushing H, Bailey P: Tumors arising from blood vessels of the brain: angiomatous malformations and hemangioblastomas. Yale J Biol Med 2:403-405, 1928 
5. Daly ME, Choi CYH, Gibbs IC, Adler JR Jr, Chang SD, Lieberson RE, et al: Tolerance of the spinal cord to stereotactic radiosurgery: insights from hemangioblastomas. Int J Radiat Oncol Biol Phys 80:213-220, 2011

6. Gibbs IC, Kamnerdsupaphon P, Ryu MR, Dodd R, Kiernan $\mathrm{M}$, Chang SD, et al: Image-guided robotic radiosurgery for spinal metastases. Radiother Oncol 82:185-190, 2007

7. Hanakita S, Koga T, Shin M, Takayanagi S, Mukasa A, Tago $\mathrm{M}$, et al: The long-term outcomes of radiosurgery for intracranial hemangioblastomas. Neuro Oncol 16:429-433, 2014

8. Hernández-Durán S, Hanft S, Komotar RJ, Manzano GR: The role of stereotactic radiosurgery in the treatment of intramedullary spinal cord neoplasms: a systematic literature review. Neurosurg Rev 39:175-183, 2016

9. Kano H, Shuto T, Iwai Y, Sheehan J, Yamamoto M, McBride HL, et al: Stereotactic radiosurgery for intracranial hemangioblastomas: a retrospective international outcome study. $\mathbf{J}$ Neurosurg 122:1469-1478, 2015

10. Karabagli H, Genc A, Karabagli P, Abacioglu U, Seker A, Kilic T: Outcomes of Gamma Knife treatment for solid intracranial hemangioblastomas. J Clin Neurosci 17:706-710, 2010

11. Lee SH, Park BJ, Kim TS, Lim YJ: Long-term follow-up clinical courses of cerebellar hemangioblastoma in von Hippel-Lindau disease: two case reports and a literature review. J Korean Neurosurg Soc 48:263-267, 2010

12. Maher ER, Yates JR, Ferguson-Smith MA: Statistical analysis of the two stage mutation model in von Hippel-Lindau disease, and in sporadic cerebellar haemangioblastoma and renal cell carcinoma. J Med Genet 27:311-314, 1990

13. Matsunaga S, Shuto T, Inomori S, Fujino H, Yamamoto I: Gamma Knife radiosurgery for intracranial haemangioblastomas. Acta Neurochir (Wien) 149:1007-1013, 2007

14. Moss JM, Choi CYH, Adler JR, Soltys SG, Gibbs IC, Chang SD: Stereotactic radiosurgical treatment of cranial and spinal hemangioblastomas. Neurosurgery 65:79-85, 2009

15. Neumann HP, Berger DP, Sigmund G, Blum U, Schmidt D, Parmer RJ, et al: Pheochromocytomas, multiple endocrine neoplasia type 2, and von Hippel-Lindau disease. N Engl J Med 329:1531-1538, 1993

16. Niemelä M, Lim YJ, Söderman M, Jääskeläinen J, Lindquist C: Gamma Knife radiosurgery in 11 hemangioblastomas. J Neurosurg 85:591-596, 1996

17. Puataweepong P, Dhanachai M, Hansasuta A, Dangprasert S, Sitathanee C, Puddhikarant P, et al: The clinical outcome of intracranial hemangioblastomas treated with linac-based stereotactic radiosurgery and radiotherapy. J Radiat Res (Tokyo) 55:761-768, 2014

18. Richard S, Campello C, Taillandier L, Parker F, Resche F: Haemangioblastoma of the central nervous system in von Hippel-Lindau disease. J Intern Med 243:547-553, 1998

19. Rubinstein LJ: Atlas of Tumor Pathology: Tumors of the Central Nervous System. Washington, DC: Armed Forces Institute of Pathology, 1972

20. Sayer FT, Nguyen J, Starke RM, Yen CP, Sheehan JP: Gamma Knife radiosurgery for intracranial hemangioblastomas- outcome at 3 years. World Neurosurg 75:99-105, 45-48, 2011

21. Selch MT, Tenn S, Agazaryan N, Lee SP, Gorgulho A, De Salles AAF: Image-guided linear accelerator-based spinal radiosurgery for hemangioblastoma. Surg Neurol Int 3:73, 2012

22. Simone CB II, Lonser RR, Ondos J, Oldfield EH, Camphausen K, Simone NL: Infratentorial craniospinal irradiation for von Hippel-Lindau: a retrospective study supporting a new treatment for patients with CNS hemangioblastomas. Neuro Oncol 13:1030-1036, 2011

23. Smalley SR, Schomberg PJ, Earle JD, Laws ERJ Jr, Scheithauer BW, O'Fallon JR: Radiotherapeutic considerations in the treatment of hemangioblastomas of the central nervous system. Int J Radiat Oncol Biol Phys 18:1165-1171, 1990

24. Sung DI, Chang CH, Harisiadis L: Cerebellar hemangioblastomas. Cancer 49:553-555, 1982

25. Zagzag D, Krishnamachary B, Yee H, Okuyama H, Chiriboga L, Ali MA, et al: Stromal cell-derived factor-1 $\alpha$ and CXCR4 expression in hemangioblastoma and clear cell-renal cell carcinoma: von Hippel-Lindau loss-of-function induces expression of a ligand and its receptor. Cancer Res 65:61786188,2005

\section{Disclosures}

The authors report no conflict of interest concerning the materials or methods used in this study or the findings specified in this paper.

\section{Author Contributions}

Conception and design: Chang, Pan, Ho. Acquisition of data: Pan, Ho, D’Astous, Sussman, Tayag, Thompson, Pangilinan. Analysis and interpretation of data: Pan, Ho. Drafting the article: Pan, Ho. Critically revising the article: Pan, Ho. Reviewed submitted version of manuscript: Chang, Pan, Ho. Statistical analysis: Pan, Ho. Administrative/technical/material support: D’Astous, Sussman, Tayag, Thompson, Pangilinan. Study supervision: Chang, Pan, Ho, D’Astous, Soltys, Gibbs.

\section{Supplemental Information \\ Videos}

Video abstract. https://vimeo.com/193878005.

Online-Only Content

Supplemental material is available online.

Supplemental Tables 1 and 2. https://thejns.org/doi/suppl/10. 3171/2016.10.FOCUS16361.

\section{Correspondence}

Steven D. Chang, Department of Neurosurgery, Stanford School of Medicine, 300 Pasteur Dr., R225 MC 5327, Stanford, CA 94305. email: sdchang@stanford.edu. 